Objectives: To assess in clinical practice the improvement in quality of life from the patient's perception as a result of pharmacological treatments in axSpA. Methods: A sample of 680 patients diagnosed with axSpA was interviewed through an online survey as part of the Spanish Atlas-2017, which aimed to promote early referral, improve healthcare, and the use of effective treatments in patients with axSpA. For this study, self-reported data from patients who had received both NSAIDs and BT were analysed. Patients were asked about the improvement they had experienced on 7 different aspects of quality of life after starting treatment with NSAIDs or BT: independence, leisure and free time, social relations, sport and physical activity, and mood and sexual relations. Improvements were measured on a 0 to 10 Likert Scale and classified as low $(\leq 5)$ and high $(\geq 6)$. Non-parametric (Wilcoxon) tests were used to compare the degree of improvement between patients with biological therapy and those with NSAIDs.

Results: A total of 189 patients who had received both types of drugs were included. The mean (SD) age was $44.03( \pm 10.11)$ years, $50.3 \%$ were females, $70.9 \%$ married and $47.1 \%$ belong to a patients' association. The mean (SD) disease duration was $21.3 \pm 10.7$ years and $67.7 \%$ were HLA-B27+. A higher percentage of patients perceived a high level of improvement after receiving a BT than after receiving an NSAID, for both overall quality of life assessment $(57 \%$ vs $22 \%$, respectively) and the different quality of life-related aspects. Additionally, the mean degree of improvement for overall quality of life assessment and the different aspects related to this were reported to be significantly higher after receiving BT than after NSAIDs (overall improvement: $5.46 \pm 2.59$ vs $3.19 \pm 2.45 ; p<0.001$, respectively).

Abstract AB0875 - Table 1. Mean improvement degree and percentage of patients who reported high improvement $(>6$ in $0-10)$ in different aspects related to quality of life after receiving biological therapy and NSAIDs

\begin{tabular}{|l|c|c|c|c|l|}
\hline & \multicolumn{2}{|c|}{ NSAID } & \multicolumn{2}{c|}{ Biological Therapy } & \\
\hline & $\begin{array}{c}\text { High } \\
\text { improvement } \\
(\%)\end{array}$ & $\begin{array}{c}\text { Degree of } \\
\text { improvement, } \\
\text { Mean (SD) }\end{array}$ & $\begin{array}{c}\text { High } \\
\text { improvement } \\
(\%)\end{array}$ & $\begin{array}{c}\text { Degree of } \\
\text { improvement, } \\
\text { Mean (SD) }\end{array}$ & $\begin{array}{c}\text { p value } \\
\text { Wilcoxon }\end{array}$ \\
\hline Independence & 22.6 & $3.40(2.79)$ & 53.0 & $5.83(3.01)$ & $<0.001$ \\
\hline Leisure \& Spare Time & 22.9 & $3.41(2.73)$ & 58.2 & $5.81(2.80)$ & $<0.001$ \\
\hline Employment & 20.7 & $3.01(2.84)$ & 53.6 & $5.48(3.36)$ & $<0.001$ \\
\hline Social Relations & 19.4 & $3.05(2.50)$ & 52.1 & $5.45(2.95)$ & $<0.001$ \\
\hline $\begin{array}{l}\text { Sport \& Physical } \\
\text { Activity }\end{array}$ & 14.4 & $2.62(2.71)$ & 41.3 & $4.88(3.05)$ & $<0.001$ \\
\hline Emotional Wellbeing & 17.4 & $2.70(2.83)$ & 53.9 & $5.78(2.88)$ & $<0.001$ \\
\hline Sexual Activity & 16.0 & $2.52(2.66)$ & $53.4)$ & $4.65(3.28)$ & $<0.001$ \\
\hline Global & 22.2 & $3.19(2.45)$ & 57.0 & $5.46(2.59)$ & $<0.001$ \\
\hline
\end{tabular}

Conclusions: In clinical practice, patients' self-reported satisfaction overall and related to different aspects of quality of life is substantially greater after being treated with BT than with NSAIDs. However, these results need to be confirmed in a longitudinal study

Acknowledgements: The Atlas was promoted by CEADE and funded by Novartis

Disclosure of Interest: M. Garrido-Cumbrera: None declared, D. Gálvez-Ruiz: None declared, J. Gratacós: None declared, C. Blanch Mur Employee of: Novartis, V. Navarro-Compán: None declared

DOI: 10.1136/annrheumdis-2018-eular.7307

\section{AB0876 CORRELATION BETWEEN FAECAL CALPROTECTIN LEVELS AND TOBACCO USE IN PATIENTS WITH SPONDYLOARTHRITIS AND WITHOUT PREVIOUS DIAGNOSIS OF INFLAMMATORY BOWEL DISEASE}

M. Espinosa Malpartida ${ }^{1}$, C. Ramos Giráldez ${ }^{1}$, C. Merino Argumánez ${ }^{1}$, M.B. RuizAntorán², J. Campos Esteban ${ }^{1}$, C. Barbadillo Mateos ${ }^{1}$, H. Godoy Tundidor ${ }^{1}$, B. Agudo Castillo ${ }^{3}$, Y. González Lama ${ }^{3}$, J.L. Andreu Sánchez ${ }^{1}$, J. Sanz Sanz ${ }^{1}$. ${ }^{1}$ Rheumatology; ${ }^{2}$ Clinical Pharmacology; ${ }^{3}$ Digestive, H. U. Puerta de Hierro Majadahonda, Madrid, Spain

Background: It is estimated that between $5 \%$ and $10 \%$ of patients with spondyloarthritis (SpA) are associated with inflammatory bowel disease (IBD). It has also been proven through endoscopic and histological studies that up to $60 \%$ of patients with SpA have microscopic inflammatory intestinal lesions, with a subclinical character and of which the true clinical relevance is unknown, although a greater percentage of these are those that will evolve to IBD.
Objectives: To assess whether tobacco use may be associated with higher faecal calprotectin (FC) levels in patients with diagnosis of SpA and without clinical suspicion or previous diagnosis of IBD.

Methods: TThis is a single centre, cross-sectional, observational study with prospective collecting data. Data were included for consecutive patients from Rheumatology consultation who had been previously diagnosed of SpA, fulfilled ASAS criteria and without digestive symptoms suggestive of IBD (chronic diarrhoea, rectal bleeding, perianal disease, chronic abdominal pain - persistent or recurrent) Details about demographic characteristics, clinical and laboratory variables related with SpA (BASDAI, HLA B27, acute phase reactants), treatments and FC were collected. A pathological cut-off point of $\mathrm{FC}>50 \mathrm{mg} / \mathrm{kg}$ was determined. Patients on NSAIDs treatment were advised to discontinue its use 2 weeks before collecting stool samples. This study was approved by the Clinical Research Ethics Committee.

Results: 99 patients were included: $53.5 \%$ women, with a mean age of $46 \pm 11$ years. nonspecific digestive disorders (dyspeptic symptoms, $\mathrm{H}$. pylori y gastroesophageal reflux) were observed in $9 \%$ of the patients. Among all, $18 \%$ were smokers. Mean BASDAI was $3.7 \pm 2.5 ; 39 \%$ of patients were being treated with any concomitant DMARD and $67 \%$ were on NSAIDs. $49.5 \%$ of the patients ${ }^{49}$ showed elevated FC determinations, with an mean level of $276 \mathrm{mg} / \mathrm{kg}$ (range 52$3,038)$. The percentage of patients with high levels of FC was significantly increased in smokers $(72.2 \%$ vs. $44.4 \%$, p. 0.033$)$, with higher levels of $F C$ in smokers than non-smokers (262 mg/L vs. $121 \mathrm{mg} / \mathrm{L}$. p. 0.126). The remaining analysed variables did not show any significant differences in terms of FC levels. Conclusions: Microscopic bowel inflammation is described in approximately $50 \%$ of patients with SpA and it is related with more severe disease. Tobacco use has been associated with worse prognosis and response to treatment in SpA. A relationship between elevated FC levels (inflammatory activity biomarker) and tobacco use in patients with SpA without previous diagnosis or clinical suspicion of IBD is established in this study.

Disclosure of Interest: None declared

DOI: 10.1136/annrheumdis-2018-eular.5979

\section{AB0877 \\ ANALYSIS OF THE ASSOCIATION OF THE PERIPHERAL INVOLVEMENT OF THE SPONDYLOARTHRITIS WITH THE EXTRA-ARTICULAR MANIFESTATIONS}

M.D.S. Mastella, I.M.S. Vale, M.M. Pereira, M.J. Carmo, G.R.W. Castro, I. A. Pereira. UNISUL, Florianópolis, Brazil

Objectives: Patients with SpA present peripheral involvement, such as arthritis and enthesitis, or only axial involvement, such as sacroiliitis and sindesmophytes The differentiation of the peripheral and axial presentation is important, being able to guide different therapeutic strategies.

Methods: This is a retrospective observational study, conducted in two clinics in Florianópolis. The population was composed of patients with AS and non-radiographic and peripheral axial SpA, according to the criteria of modified New York and ASAS group, respectively, served from 1997 to 2017.

Results: 153 patients were analysed, 82 were male (53.59\%), $71.29 \%$ were HLA B27 positive (77/108 tested), $87.3 \%$ had sacroiliitis detected on $\mathrm{x}$-ray, CT or MRI 104 presented peripheral involvement $(67.97 \%)$ and $49(32.02 \%)$ purely axial involvement. Arthritis occurred in $86(56.2 \%)$ and enthesitis in $57(37.3 \%)$ patients. The use of synthetic DMARD occurred in $78.4 \%$ of the patients, more frequently in the group with peripheral involvement, with methotrexate being used in $74 \%$ versus $56.3 \%$ of those with purely axial involvement $(p<0.05)$. The use of biological DMARD occurred in 104 (68\%), in the majority of the anti-TNF class (96.1\%), with the highest frequency of use in patients with axial involvement $(77.1 \%$ versus $64.4 \%$ ), but not statistically significant $(p>0.05)$. Extra-articular manifestations were found in $72(47.1 \%)$ of the patients, with uveitis being the most frequent (26.8\%). The presence of uveitis occurred in $68.3 \%$ of patients with isolated axial involvement versus $31.7 \%$ of patients with peripheral involvement $(p=0.179)$. The cutaneous involvement occurred in $18.3 \%$ of the patients with peripheral involvement compared to $8.3 \%$ of those with an isolated axial condition. Regarding bowe involvement and cardiovascular impairment, there was no significant difference in prevalence between the two groups.

Conclusions: Extra-articular manifestations are frequent in $\mathrm{SpA}$, but are not more frequent in patients with peripheral involvement versus patients with pure axial involvement. Peripheral involvement is associated with greater use of synthetic DMARDs when compared to pure axial involvement.

Disclosure of Interest: None declared

DOI: 10.1136/annrheumdis-2018-eular.1652 